\title{
Transformation through expeditionary change using online learning and competence-building technologies
}

\author{
Donald M. Norris ${ }^{\mathrm{a}}$ and Paul Lefrere ${ }^{\mathrm{b} *}$ \\ ${ }^{a}$ Strategic Initiatives, Inc., Herndon, Virgina, USA; ${ }^{b}$ Knowledge Media Institute, Open \\ University, Milton Keynes, UK
}

(Received 14 February 2010; final version received 2 September 2010)

\begin{abstract}
This paper presents a patterns-based model of the evolution of learning and competence-building technologies, grounded in examples of current practice. The model imagines five simple stages in how institutions use 'expeditionary change' to innovate more nimbly. It builds upon three assertions. First, the pervasiveness of web-based knowledge-sharing in higher education's communities, observatories and social networks makes it easier to: introduce relevant technologies, find people doing similar things, learn from their experiences, find and collaborate with early adopters of learning technologies, hear about relevant innovations, and discover and exploit news of opportunities, threats and trends. Second, expeditionary change based on such knowledge-sharing facilitates transformations in: production functions for learning, roles of faculty and mentors, business models, patterns and cadences of interactivity, use of open resources, and the roles of learners. Third, those transformations make it easier for disruptive forms of higher education to emerge; for example, dynamically updated curricula that address emerging and important knowledge gaps, and thereby increase students' employability.
\end{abstract}

Keywords: online education; organisational transformation; expeditionary planning

\section{Introduction}

Calls for expeditionary change and for knowledge-sharing during the re-design of technology-supported courses are not new. We argue that pressures on higher education require paying more attention to them. Issues include how higher education can re-align, re-design, re-define, and re-engineer itself, link work and learning (Norris and Dolence 1995), leverage technology to cut costs (Baumol and Bateman 1995), reinvent courses and change patterns of interaction (Twigg 2010). Many campuses have achieved some re-invention of practices, improving learner outcomes. Knowledgesharing makes it easier to hear of further improvements and deploy them systemically and early enough to permit low-pain change. Change becomes less coherent where knowledge-sharing is low and campuses use e-technologies in low-value ways, digitising existing approaches to teaching, rather than exploring "... new experiences and value propositions that could be created for students, faculty, staff, and other stakeholders. ... leveraging ... resources in new ways" (Norris 2005, 687 ). Sloan-C typifies

\footnotetext{
*Corresponding author. Email: p.lefrere@open.ac.uk
} 
this variety of practice. Its audiences include organisations focused on the mainstreaming of online learning, rather than the potential of online practices to deconstruct and re-invent educational practices; and early adopters of suggestions about where and how to effect transformation (Norris and Dolence 1995), re-aligning and re-engineering their processes, changing business models, and re-shaping practice.

\section{Understand the entire population, learn from the leaders}

While one must understand the full spectrum of e-learning practice, real insights into possible breakthrough practices come from the practice leaders.

\section{Online, blended, and e-learning, broadly practised}

Here is a stereotypic depiction of the evolution of online learning.

Replicate courses and curriculum practices in an online mode, adjusting for differences between online and face-to-face experiences. Progressively improve and enhance the online and blended learning offers, combining online and physical elements to create more engaging student experiences. Use blended learning to reduce the need for classroom space and change pedagogical practices. Incorporate lessons learned to enhance all face-to-face instruction with proven technology, resources and techniques. Leverage technology-supported learning offerings and interaction channels (e.g. handheld devices used for mobile learning) to attract adult learners and students who are working at least part-time.

Transformation and knowledge-sharing, combined, shorten or bypass some of those stages.

\section{Who and where are the leaders?}

Globally, we see increased $R \& D$ capacity (taking this as a proxy measure for ability to innovate in the use of online learning) and increased access to the Web (and the information available through using it). Universal web access supports a shift toward greater reliance on informal local communities of practice and web-based and crossborder knowledge-sharing, and a shift away from peer-reviewed articles as the definitive source of accounts of experiences of successes in online learning and in the early adoption of transformational innovations at the course or subject level. This reduces the barriers to knowledge diffusion and appropriation, speeds up the knowledge flow to/from/within developing nations and makes it easier for locally-proven innovations to diffuse fast, without passing through information gatekeepers. We suspect (but do not have hard data) that easier access to experiences of online learning is making it easier to bypass stages outlined in the stereotypic depiction above of the evolution of online learning. We expect a similar bypassing pattern to apply to transformation at the institutional level, accompanied by easier and faster access to insights gained elsewhere into the effects of making combinations of changes. This brings the prospect of empowering institutions to model possible changes in advance (e.g. unbundling traditional elements of teaching and accreditation, and re-inventing faculty roles). It is important to find out fast and cheaply how to exploit the insights from a model and deliver the anticipated benefits in reality, on time and within budget. Also needed are ways to enable institutions to monitor the external environment, to track and respond 
to changes in the demand for their courses and for graduates of those courses and, if necessary, to fundamentally change their educational goals, audience, mode of operation, business model and price points.

\section{Why has online learning become even more strategic?}

Online learning has progressively come to be regarded as equivalent or even superior in some ways to traditional, face-to-face learning. As predicted in Norris and Dolence (1995) and Baumol and Bateman (1995), today's mass higher education is becoming unaffordable. Transformed versions of online, blended and e-learning hold the potential to be essential elements of reimagining higher education, making it sustainable.

Transformed online, blended, and e-learning can raise throughput and institutional efficiency (Norris and Baer 2009), cutting the marginal cost of tuition significantly. If savings are passed onto learners, more people can afford to enter higher education. Demand for places will be stimulated further if transformations address ease of learning, shorten time to competence, and strengthen links between learning experiences and competences authentic to the workplace. The capacity to do this is enhanced with online learning and Web 2.0 tools and patterns of interactivity.

\section{Two evolutionary transformations in the models of learning and competence-building}

First, there is the evolution of the business models for institutions and formal learning enterprises from today's traditional premium price model (bundled learning, assessment, and certification; a focus on what constitutes a quality education/institution; and traditional roles for faculty) to a transformed model (unbundled and re-imagined teaching, learning, assessment, and certification; value-based in times of scarce resources; re-invented roles for faculty, mentors, instructional designers, and peer-topeer learning; and changing the financial model to achieve financial sustainability and lower prices to the consumer).

Second, there is the evolution of the learning setting from the traditional institutional setting to a transformed, open setting in which 'open' includes, but is not limited to, open educational resources (OER). Open also means that users have more choice about what they learn (not just prescribed learning pathways but knowledge gaps, based on flows of continuously refreshed knowledge), how they learn it, what if anything they pay for it and who they learn it with/from (e.g. peer-to-peer learning and community of practice-based learning). Some of these transformations are being incorporated into traditional institutional settings. Others are occurring outside the realm of accredited institutions and formal learning enterprises.

In Figure 1 we identify five simplified (stereotypic) patterns of business models for online learning. In some institutions, elements of all five patterns exist (or have been tried). In others, the patterns have been tried sequentially (like stages in a transformation). To simplify discussion, from here on we call the patterns 'Stages', to capture their increasing sophistication and the potential for using them as models for discussing possible transformations.

The horizontal axis represents progressive sophistication of business models toward greater value and financial sustainability. The vertical axis represents progressive expansion of open learning practices, both within traditional institutions (represented by the expansion of the 'institutional arrow' in each successive stage) and in emerging 


\section{Evolving Models of Learning and Competence Building}

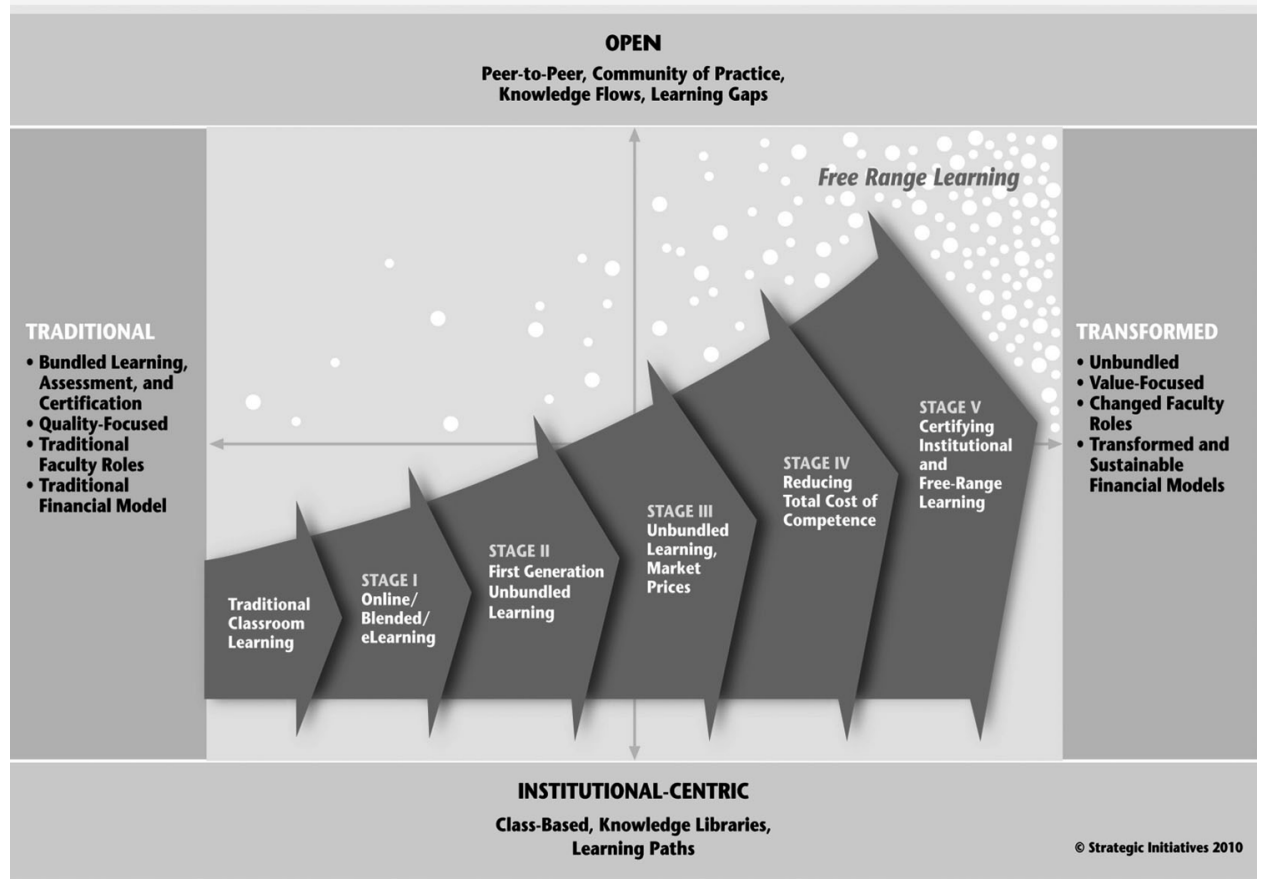

Figure 1. Evolving models of learning and competence-building.

peer-to-peer environments, communities of practice, focus on knowledge gaps and flows, and 'free range learning'.

This simplified diagram presents these stages as logical, sequential stages of evolution for describing the current state of development of online practices. The reality is substantially more complex. First, individual institutions may demonstrate characteristics of several stages at any point in time. Second, individual institutions may experience a jump shift and make a leap from Stage I to Stages III or IV if they achieve strong leadership, learn from the best practices of others, and develop or acquire infrastructures, processes and competences. And third, the boundaries between institutional and open learning experiences will blur as institutional practice evolves into States IV and V.

\section{Stage I: online/blended/e-learning innovations}

Traditional institutions enable their faculty to put courses online and progressively create various forms of online, blended and e-learning offerings under the institutional brand. These offerings are often more expensive to develop and launch than the traditional institutional offerings. They do not achieve breakthrough economies, may use traditional or adjunct faculty, and replicate many existing practices. They do not use technology to truly transform faculty roles and patterns of interactivity. 
This pattern represents a transitional state or stage, not sustainable in the face of competition.

Online/blended/e-learning innovations can reduce the overall cost to students and the institution, even if the tuition charged to students is the same as or greater than the tuition for face-to-face instruction. Online students not only save on transportation costs, they reduce the opportunity costs of travel time, lost income and such. These can be significant savings. Blended learning can save institutions the cost of new facilities by reducing classroom demand and allowing institutions to reduce the impact of commuter student traffic and use of on-campus facilities and services. Campuses in metropolitan areas use combinations of online, blended, and e-learning to 'sculpt' enrolments at their multiple physical campuses and in virtual learning spaces.

Technology can be used to unbundle and transform the existing classroom-centric model for individual courses. Course re-invention (Twigg 2010) can improve performance and student success and reduce costs. Some institutions are scaling these processes to departmental, institution, or even system level, reducing costs systemically without diminishing quality.

Individual course re-invention is not sufficient to meet the challenges of establishing financial sustainability. Sustainable online learning requires pervasive adoption of unbundling, re-invention and a value focus to the entire online learning enterprise.

Many institutions remain stuck in the 'digitise-the-traditional-but-don't-re-invent' stage of development. In the 2009 Managing Online Programs Survey (Green 2009), most institutions were still searching for satisfactory, sustainable models for organising and delivering online learning. They will continue to search fruitlessly unless they apply the following principle. The key to evolving new, sustainable models for online learning is to utilise technology to:

- unbundle and re-invent teaching, learning, assessment and certification;

- focus on value, not just quality;

- change the use and roles of faculty, mentors and peer-to-peer learning; and

- transform business models by: continuously seeking new income streams that can mitigate the need to continuously increase tuition to fill revenue gaps, reducing operational overhead (i.e. new buildings, parking lots, dorms) and other costs, seeking lower price points and enabling more rapid completion of learning objectives, and reducing the total cost of achieving learning goals.

Online, blended and e-learning innovators can move on to transformation via Stages II-V.

\section{Stage II: first-generation unbundled offerings}

In addition to unbundled offering, this pattern features re-invented business practices (e.g. using mentors, not expert in content, rather than traditional, tenure-track faculty), production function (using team-developed resources to create courses) and business models (high-quality, high-value online support services).

The elements of this pattern may be seen at the same time as the elements in the pattern in Stage I, but have a different focus: consistent, demonstrable outcomes and learning experiences attuned to the needs of working adults. The focus can yield lower production/delivery costs per student, if close attention is paid to viable class size (to achieve economies of scale, without sacrificing quality of engagement and outcomes) 
and to reducing unneeded variability (courses utilise a similar approach to ensure consistency and quality of learning outcomes that, in turn allows for continuous improvements, refinements and ability to quickly incorporate new industry competencies; this practice affords economies of scope). At the same time, institutions sominded can charge for the extra value they provide learners (linked courses taken sequentially, accelerated time to degree, lack of family/work barriers, and premium online services). The higher resulting margin (difference between price and actual cost) is invested in extending institutional brand, business/industry market research and innovations in certification and instructional technology/systems development to handle competition at the low end (from no-fee systems) and at the high end (from innovators who migrate to a more competence-based approach with higher perceived value for learners).

\section{Stage III: unbundled learning, market competitive pricing}

This is becoming established in the United States. There, institutions like the Western Governors University, Florida State College at Jacksonville's Open College and Lamar University have re-invented the production function and faculty roles to cut marginal costs (so achieving financial advantages realised by for-profits). They have used technology to meet learner needs better, unbundling and re-inventing teaching, learning, assessment and accreditation.

\section{Stage IV: reducing the total cost of competence}

Through incremental innovations, including increased use of OER (see, for example, D'Antoni and Savage 2009) and refinements in online learning, providers offer fast, fluid, flexible and affordable options, competing on the following dimensions:

- Enjoyment: create better, more amenable, and more effective, engaging learning and support experiences.

- Outcomes: programmes linked to highly valued, demonstrable competences and employability success.

- Price: decrease tuition and fees, accelerate pace of completion and thereby reduce "total cost of competence".

- Time: reduce time to achieve competence objectives, certificates and degrees.

- Flexibility: accredit a wider range of institutions and experiences.

- Tracking change: provide graduates with social-networking-based mechanisms for refreshing and maintaining their competences on an ongoing basis. Treat alumni associations as networks and communities of practice in particular disciplines. This could lead to online graduate programmes with a "competency observatory" for alumni, identifying emerging competences before they are standard industry practice/requirements.

These options affect for-profits as well as traditional institutions. Stage IV examples of reducing the time to degree include:

- giving credit for prior learning more effectively and extensively;

- achieving competency-based approaches that unbundle and give credit for already-acquired, demonstrated competences; and 
- improving K-12 preparation for college-level work through P-20 improvement initiatives and partnerships that reduce the total cost of learning, over time.

In Stage IV, open learning practices are incorporated into institutional offerings and are accepted for credit if they involve 'recognised' providers (accredited with established articulation agreements). Institutions focus on developing infrastructure, support services, processes and reward systems necessary to support these efforts.

\section{Stage V: certifying both institutional and free-range learning}

Figure 1 illustrates that with each successive pattern (or stage, if you prefer), institutional learning also expands upward, embracing more open learning techniques within institutional learning practices. In patterns like Stage V, institutions incorporate open learning practices into their offerings and accept and certify high-value outcomes provided by other institutions. In addition, selected leaders develop or acquire the capacity to certify free-range learning and competence-building pursued by individuals independent of formal institutions. This is a natural extension of the credit-forprior-learning and competence-based-learning movements. Not all institutions will have the infrastructures, practices, processes and core competences to become certification agencies for learning. Such agencies would probably charge a certification fee for conferring a degree for learning achieved elsewhere, in order to award valued certificates or degrees. This will prove attractive as peer-to-peer and 'free range' learning opportunities develop (e.g. home-schooled, self-taught or educated in a non-accredited institution in another country). It is precisely the growth of non-institutional learning opportunities that is the second vector of evolution in e-learning methods, models and practices.

\section{Evolution of learning settings from institutional to open}

The learning settings described in the first vector of evolution are institutional: traditional colleges and universities (including their extension and continuing education divisions), for-profit universities and learning enterprises in corporations. These socalled 'institutional' settings will continue to be the primary players in traditional learning. But they will see their dominance shrink in the face of open learning environments that are the property of the student, not the institution. The challenge institutions face is to keep pace with the changing nature of knowledge and competence, and the move toward greater value in learning and competence-building experiences. Over time, open learning with a free-range learner at the centre of a personal learning environment will dominate (ROLE Project 2010).

Clear evolutionary 'stages' of open learning have not yet revealed themselves. Some new forms of open learning environments and experiences are described below.

\section{Peer-to-peer voluntary associations}

There is a movement toward high-tech, do-it-yourself education (Kamenetz 2009). Some experiments reside within existing institutional settings, such as classes structured like role-playing and serious games that are being tested out in universities across the globe. Others are occurring in start-up organisations, like Peer2Peer University and the University of the People, attempting to bridge the gap between free 
online materials and low-cost education. Peer2Peer University uses a website to enable would-be-students to convene and schedule courses, meet online, and tutor one another, all facilitated by a volunteer. This is a demonstration of concept. University of the People has enrolled the first class of 300 students from nearly 100 countries. The founder's goal is to offer bachelor's degrees in business and computer science using open courseware and volunteer faculty for a price of about $\$ 4000$ for a four-year degree. Other pundits, such as Richard Vedder, have mused about associate degrees for as little as $\$ 2000$ (low by US or UK standards, but not globally).

\section{Formal communities of practice}

Informal and formal communities of practice are common in the world of business and professional practice (Norris, Mason, and Lefrere 2003; MSU 2010; Brown and Adler 2008). One advantage of learning based on real communities of practices is the capacity to receive early warning of the emerging competences needed in particular fields of endeavour. Communities of practice can identify, promote and develop fresh competences fast among large bodies of participating practitioners. These sorts of communities will become the focal points for open learning experiences in the future. An example is the Food Safety Knowledge Network (MSU 2010), a partnership between a not-for-profit group and a university to efficiently and effectively teach competency at all levels of food safety. The partnership will use open resource techniques (social networking, dynamic knowledge sharing and evaluation tools) to harmonise standards, practices and training criteria, and to create a curriculum for food safety competency through partnerships with industry, government, academia, local/ regional authorities, and other stakeholders. Coupled with a unique learning environment using face-to-face sessions, seminars, formal courses and online learning, it will present a low-cost, fast and efficient way for professionals to achieve competence across all sectors of the food safety industry. New knowledge will enter such networks via open knowledge flows such as pioneered in OpenTox (Hardy et al. 2010).

\section{Free-range open learning}

Over time, individual learners will have access to a vast constellation of open learning experiences and resources. These will range from formal communities of practice and competence-building networks, to easily configured, temporary learning cohorts. In Europe, partnerships to develop relevant knowledge-sharing tools and experiences are under development between universities and business/industry (a primary source of information on the skills that graduates need to be employable); for example, the ROLE project. Individuals will be able to develop, maintain and extend their competence in a variety of ways and at very reasonable prices, or even at no cost. Even when 'mature', this array of alternatives will change, adapt and improve faster than any single institution can match today (just as there is no ' $\mathrm{I}$ ' in team, there is no 'academic senate' or 'curriculum committee' in open learning).

Certification is one link between the two evolutional paths of learning and competence. Open learning environments and experiences will interact with institutional learning, assessment and certification experiences. Institutions that do an excellent job of competence-based learning may become certifying entities charging to authenticate competences acquired through open learning, and to award credit, certificates and degrees. 
As recently summarised by Johansen (2009), many more examples exist across the globe, in open learning experiments, prototypes and expeditions. An apt set of questions may be: which government(s) or corporate entities from across the globe will invest in open resources in the future? Will they do so in a manner that will disrupt traditional offerings and create opportunities for continuing re-invention of learning and competence building? How will this foment a change in the balance of competence power and the competition for talent across the globe?

\section{Many models, competing for learners}

To quote an anonymous referee: "The basic fact is that current modes of education provision are becoming both unaffordable and unattainable as a function of massively widening participation". This conundrum can be resolved through concurrent reinvention of the supplier-related aspects (e.g. higher education's elements, audiences and cost structures) and the consumer-related aspects (e.g. the need to minimise the cost of the investment in higher education by a learner or sponsor, minimise the risk of receiving an unacceptable level of return on that investment, maximise the statistically likely future benefits from that investment, and optimise the cash flow aspects of the investment and the return). In our view, re-inventions that yield those outcomes become increasingly possible as institutions move through the stages in our model.

Stage I patterns include digitising the traditional, so is not likely to cut costs and add value in significant ways. It may even add to costs. By contrast, Stage V patterns bring the prospect of learners and institutions being able to use online learning to personalise a learner's path (e.g. the courses they take, the skills and qualifications they acquire), so that desired outcomes are highly likely. 'Experience effects' achieved through repeated refinements of processes are likely to be seen in online learning and in sharing knowledge, so the cost of that personalisation could fall significantly. Likewise, changes in cost structures are likely. Free-range self-study using OER and peer-to-peer support could drastically cut, even to zero, the cost of acquiring the knowledge and skills associated with the early years of higher education. Later years would still have to be paid for, but links with communities of practice (informal online resources) would make it easier for students to find out 'what is hot and what is not' in the world of work, before signing up for a vocational course. It would enable institutions to deliver more to learners, in the sense of helping them to achieve morevalued outcomes such as offers of more interesting work, with more of a future, and delivering greater value for society. They might wish to charge a premium for courses that deliver those results. From a learner's perspective, optimisation of that kind requires better preparation: to choose between paid-for courses, to learn more from their chosen courses, and effective support in gaining the anticipated benefits.

Affordability of online learning becomes more achievable with reductions in an institution's historic costs. This is increasingly feasible as institutions move from Stage I in our model to Stage V. Most of the world's higher education institutions have not yet reached Stage I, and may never do so. They are traditional institutions, illprepared for the challenges and scenarios identified in studies of higher education challenges (for example, OECD 2006; Looney 2009; PIAAC 2009) and the use of OER (for example, D'Antoni and Savage 2009). They have a rising cost base, declining enrolments, and lack resources to introduce modern online technologies or to appropriate modern OER that are more likely than their dated syllabi to help their students find work, but require better-trained staff, more facilities, and improved 
teaching methods. Despite their weakening position, those traditional institutions keep going; in some cases by receiving bequests, sponsorship or bail-out funding, and in other cases through special circumstances (e.g. serve a politically-important region, so cannot be closed by government).

Different patterns in our model represent different levels of innovation. Moving between patterns (stages) represents a shift across the boundary between one combination of institutional capabilities and another, crossing barriers that constrain what an institution can offer, to whom, at what cost. The barriers can be of many types; for example, barriers of accessibility, accreditation, age of learners, capability, cost, culture, disciplines, gender, language, pre-conceptions, pre-requisites, time. Institutions can use online teaching in ways that not only cross the above barriers but raise the profile of the institution and its learners, and help to increase knowledge-sharing and integration between the institution, its students, its alumni, its sponsors and its communities. If the institution does not set an over-high premium on its course costs, it can attract more students (economies of scale), in more subject areas (economies of scope), in wider catchment areas (reaching across national or international boundaries).

It will be possible for institutions to learn from emerging best practices and skip stages of evolution. In particular, institutions that aggressively practise online, blended, and e-learning at Stage I can raise their sights and transform their practices to make a jump shift to Stages III and IV, with further evolution to Stage V.

\section{Multi-faceted evolution of open knowledge}

Just as learning is evolving from 'institutional' to 'open', knowledge is undergoing its own evolution on two dimensions (Norris, Mason, and Lefrere 2003). First, the 2.0 world of knowledge is changing the predominant focus from knowledge as a 'thing' or a 'stock' of carefully marshalled, explicit knowledge resources in repositories to knowledge as a 'flow', captured through conversations and interactions with communities (Hagel and Brown 2010). Second, while traditional, degree-based learning experiences have provided carefully drawn 'knowledge paths' (including paths that result in high levels of graduate unemployment), the 2.0 world is favouring learning that fills specific 'knowledge gaps' (including gaps that correspond to employment opportunities that become more apparent through discussions in 2.0 networks). These two vectors of evolution will accelerate the emergence of Stage $\mathrm{V}$ in the evolution of online learning.

\section{From knowledge stocks to knowledge flows}

Every industry should re-imagine its basic principles and practices, from protecting and extracting value from stable, existing knowledge stocks, to a world where the focus of value creation is in effective participation in knowledge flows, which are continuously renewed (Habel and Brown 2010). These knowledge flows are created through communities of practice and social network-based collaborative spaces in professions, industries, commercial enterprises, civic and philanthropic organisations, and educational enterprises. For example, an open community for sense-making discusses interpretations and experiences of using relevant tools for sense-making (Knowledge Media Institute 2010). The ascendance of such open knowledge flows renders obsolete the institutionalised, course-based knowledge stocks that change at the pace of curriculum committee review. 


\section{From knowledge paths to knowledge gaps}

Traditional higher learning is based on defined learning paths, pre-ordered routes where the teacher passes knowledge to the students, who absorb it and try to apply it to their own pre-existing knowledge in the subject. These structured learning and knowledge paths suit early-stage learners who need to complete a prescribed course of student study, but not adults who experience rapidly changing knowledge flows or need to fill specific knowledge gaps, rapidly and for immediate application, using stored knowledge, intuition, problem-solving, creativity and adaptability.

\section{Conclusions}

At this time of flux, practitioners of online learning, blended learning and e-learning need to leverage innovations and transform practices and business models, using an 'expeditionary' approach to such change (Hamel and Prahalad 1991), tuned to higher education (Mayadas 2009), via 'radical incrementalism' (Hagel and Brown 2005) taking incremental, expeditionary steps (e.g. patterns like Stages I-V in our model), with radical intent. The expeditionary approach to learning and competence building depends on the following principles:

- Do not invest in expensive technology architectures and market-research-based solutions that require extensive planning, picking winners before informed judgements can be made, and expecting immediate success; expeditionary initiatives need to be fast, fluid, flexible and affordable.

- Recognise that Web-based, open, learner-centred learning and competence building require continuous experimentation, refinement and re-invention in response to emerging needs.

- Launch web-based mash-ups and communities of practice as 'expeditions' relying on learners and participants to continuously provide feedback on what is working and what is needed in the near future.

- Respond aggressively to knowledge flows and gaps and to combinations of innovation, entrepreneurship, employability and problem-solving that have eluded traditional institutions.

- Focus on outcomes and value (outcomes, experience in which they are achieved, and price), not processes and quality.

The learning and competence coaches, providers and mentors who will be successful in Stages IV and V of the evolution of e-learning and competence-building will follow these principles.

\section{Acknowledgements}

The authors appreciate comments by anonymous reviewers, and also insights provided by practitioners at the National Center for Academic Transformation, University of Central Florida, Capella University, Florida University at Jacksonville, Western Governors' University, Michigan State University, Oregon Open Campus and the Open University, and participants in R\&D in online learning in the European Network of Excellence STELLAR and the ROLE project (supported by the European Commission, in the theme ICT-2007 Digital Libraries and Technology-enhanced Learning, as a Large-scale Integrating Project, under the 7th Framework Programme; grant agreement number 231396). 


\section{References}

Baumol, W.J., and S.A.B. Bateman. 1995. How to think about rising college cost. Planning for Higher Education 23, no. 4: 1-7.

Brown, J.S., and R.P. Adler. 2008. Minds on fire: Open education, the long tail, and learning 2.0. EDUCAUSE Review 43, no. 1: 16-32.

D'Antoni, S., and C. Savage. 2009. Open educational resources: Conversations in cyberspace. Paris: UNESCO Publishing.

Green, K.C. 2009. Managing online programs. Presentation at the WCET Meeting, October 28. http://www.facultyfocus.com/seminars/critical-new-findings-from-the-managing-onlineeducation-study/?aa $=9019$.

Hagel, J., and J.S. Brown. 2005. The only sustainable edge: Why business strategy depends on productive friction and dynamic specialization. Cambridge, MA: Harvard Business School Press.

Hagel, III, J., J.S. Brown, and L. Davidson. 2010. Harvard Business School blog, 'Measuring The Big Shift'. June 19. http://blogs.hbr.org/bigshift/2009/06/measuring-the-big-shift.html.

Hamel, G., and C.K. Prahalad. 1991. Corporate imagination and expeditionary marketing. Harvard Business Review 69, no. 4: 81-92.

Hardy, B., N. Douglas, C. Helma, M. Rautenberg, N. Jeliazkova, V. Jeliazkov, I. Nikolova et al. 2010. Collaborative development of predictive toxicology applications. Journal of Cheminformatics 2, no. 7. http://www.jcheminf.com/content/2/1/7.

Johansen, J.K. 2009. The impact of opencourseware on paid enrollment in distance learning courses. Doctoral Thesis, Brigham Young University. http://contentdm.lib.byu.edu/ETD/ image/etd3317.pdf.

Kamenetz, A. 2009. How web-savvy edupunks are transforming American higher education. September 1. http://www.fastcompany.com/magazine/138/who-needs-harvard.html.

Knowledge Media Institute. 2010. Open sensemaking communities. http://projects.kmi.open. ac.uk/osc/.

Looney, J. 2009. Assessment and innovation in education. OECD Education Working Papers No. 24. Paris: OECD Publishing. doi: 10.1787/222814543073.

Mayadas, F.A. 2009. Speech at the 15th Annual Meeting, Sloan C Consortium, October, in Orlando, FL.

MSU. 2010. Global food safety network. http://FoodSafetyKnowledgeNetwork.org.

Norris, D.M. 2005. Driving systemic change with e-learning. In Encyclopedia of distance learning, ed. C. Howard, J.V. Boettcher, L. Justice, K. Schenk, P.L. Rogers, and G.A. Berg, 687-95. Hershey, PA: Idea Group.

Norris, D.M., and L. Baer. 2009. Linking analytics to lifting out of recession. White Paper. http://www.strategicinitiatives.com/documents/Linking_Analytics_26sep09.pdf.

Norris, D.M., and M.D. Dolence. 1995. Transforming higher education, a vision for learning in the 21st Century. Ann Arbor, MI: Society for College and University Planning.

Norris, D.M., J. Mason, and P. Lefrere. 2003. Transforming eKnowledge: A revolution in knowledge sharing. Ann Arbor, MI: Society for College and University Planning.

OECD. 2006. Four scenarios for higher education systems. Briefing paper for OECD Education Ministers. http://www.oecd.org/document/8/0,3343,en_2649_35845581_37031944_1_1_ $1 \_1,00$. html.

PIAAC. 2009. PIAAC problem solving in technology-rich environments: A conceptual framework. OECD Education Working Papers No. 36. Paris: OECD Publishing. doi: 10.1787/ 220262483674.

ROLE Project. 2010. Responsive open learning environments. http://www.role-project.eu.

Twigg, C. 2010. Course re-design initiatives. National Center for Academic Transformation. http://www.thencat.org. 